\title{
The pathology of bronchial and pleural biopsies of patients presenting to a tertiary chest clinic in Sri Lanka
}

\author{
M M A Jayawickrama ${ }^{1}$, M D S Lokuhetty ${ }^{2}$, A K C P Amarasinghe ${ }^{3}$, M J Fernando'.
}

\begin{abstract}
Introduction: Respiratory diseases are the second leading cause of hospitalization and is a significant cause of morbidity and mortality in Sri Lanka.

Objective: To describe the pathology of bronchial and pleural biopsies in patients referred to a tertiary chest clinic in Sri Lanka.

Method: This retrospective study included 127 patients subjected to bronchial or pleural biopsy at the Chest Clinic Kalutara, from January 1998 to April 2000. Histology slides were reviewed at a conference microscope. The clinical details were obtained from the clinic files.

Results: There were 101 bronchial and 26 pleural biopsies. Twenty five (19.7\%) had neoplasms, all seen in bronchial biopsies. These comprised 11 squamous, 8 adeno, 5 poorly differentiated non-small cell and one adenoidcystic carcinoma. Of the non-neoplastic group $20(15.7 \%)$ had pneumonia and its complications. Eighteen (14.2\%) had biopsy confirmed tuberculosis, of these 14 were in pleural biopsies and 4 in bronchial biopsies. Other lesions included fibrosis with chronic inflammation $4(3.1 \%)$, interstitial fibrosis $4(3.1 \%)$, fungal infections $3(2.4 \%)$ and chronic inflammation 16 $(12.6 \%)$. Twenty $(15.7 \%)$ had non-diagnostic biopsies and normal lung was seen in $17(13.4 \%)$ cases.

Conclusion: Neoplasms were the most commonly encountered lesion in our study. How ever non-neoplastic conditions were also an important cause of morbidity in this group of patients.
\end{abstract}

\section{Introduction}

Respiratory diseases are the second leading cause of hospitalization in Sri Lanka and are a significant cause of morbidity in the community due to loss of working hours and the impact of chronic respiratory disease on the quality of life. It is the seventh leading cause of hospital deaths ( 9 per $100,000)$ among adults and the third leading cause of deaths among children of 1-4 year age group (13 per 100,000$)(1)$.

The aim of this study is to determine disease patterns encountered in bronchial and pleural biopsies of patients presenting to a tertiary chest clinic in Sri Lanka.

\section{Method}

This retrospective study included 127 patients subjected to bronchial biopsy using the flexible fibreoptic bronchoscope or needle biopsy of the pleura at the chest clinic and ward of the General Hospital Kalutara from January 1998 to April 2000. Histopathology and cytology slides were reviewed at a conference microscope and the pathology was categorized as neoplastic, pneumonia and its complication, tuberculosis, chronic inflammation, fibrosis with chronic inflammation, fungal infections, interstitial fibrosis, normal histology and non diagnostic. Details of other investigations done were obtained from the clinic files.

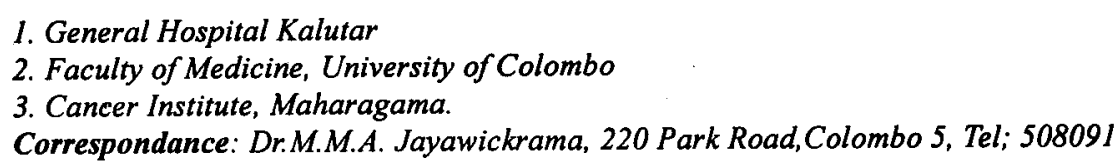




\section{Results}

There were 101 bronchial biopsies and 26 pleural biopsies of 127 patients. Neoplasms were seen in 25 patients $(19.7 \%)$. Pneumonis and its complications were seen in 20 patients $(15.7 \%)$, Tuberculosis $18(14.2 \%)$, chronic inflammation in $16(12.6 \%)$. fibrosis with chronic inflammation in $4(3.1 \%)$, fungal infection in $3(2.4 \%)$, interstitial fibrosis in $4(3.1 \%)$. The biopsy was non-diagnostic in $20(15.7 \%)$ and normal lung histology was seen in $17(13.4 \%)$ biopsies. Neoplasms were encountcred only in bronchial biopsies. The histology type, age range, sex distribution and cytology of bronchial wash and brush in biopsice of this group are shown in Table 1.Of the 18 patients $(14.8 \%)$ with tuberculosis 14 were in pleural biopsies. The chest $X$ rays of these patients showed a unilateral pleural effusion with equal distribution on the left and right side. Four cases of tuberculosis was diagnosed on bronchial biopsy and the $X$ rays of all these patients showed bilnteral milliary mottling.

In the patients with pncumonia $45 \%$ had resolving preumonis, $30 \%$ had unresolved pncomnia with abscess formation, $20 \%$ had interstitial pneumonia and $5 \%$ had lung abscess formation.

Of the three cases of fungal infections, Aspergilloma was seen in two cases showing branched hyphac at acute angkes (ligure 1) staining positive with periodic acid shiff (PAS) stain. The other case showed rounded spores staining positive with Grocorts stain.
The biopsy material was non-diagnostic in 18 $(14.3 \%)$ of patients. Of these the tissue sampled was insufficient for diagnosis in $72.3 \%$, there was absence of tissue after processing in $11.1 \%$, only a blood clot was seen in $11.1 \%$ and degenerated tissue was seen in $5.5 \%$.

\section{Discussion}

Neoplasms were the most commonly diagnosed losions in the bronchial biopsy of patients presenting to this tertiary chest elinic. These patients were reterred from medical wards and olher nearby hospitals. Eighty percent of these patients were male and they all gave a history of cigarette smoking (2). At the time of bronchoscopy bronchial wash and brush samples were taken for cytoloysy and showed malignant cells in $80 \%$ of patients.

Of the non-neoplastic lesions, the common pathological entities included tuberculosis and chronic inflammation. Most patienls with tuberculosis had a pleural effusion and pleural biopsy was helpful in confirming the diagnosis.

With the emergence of new organisms and development of drug resistance by bacteria and mycobactoria showing adaptation to theenvironment $(3,4)$ and inereased susceptibility to infections in the acquired immune deficient (AIDS) population suberculosis imposes a major problem in respiratory diseases $(5,6)$ with global dissemination of mycobacterium tuberculosis (7). There were 8000 new cascs of tuberculosis diagnosed in Sri Lanka in the year 2000 of which $80 \%$ werc pulmonary tuberculosis (8).

Table 1- The histology type, age range distribution and cytopathology of bronchial wash and brush samples of neoplastic lesions $(n=25)$

\begin{tabular}{|c|c|c|c|c|c|c|c|}
\hline \multirow[t]{2}{*}{ Histology } & \multirow[t]{2}{*}{ No } & \multirow[t]{2}{*}{$\%$} & \multirow[t]{2}{*}{ Age Range } & \multicolumn{2}{|c|}{ Sex } & \multicolumn{2}{|c|}{ Malignant cells } \\
\hline & & & & $\mathrm{M}$ & $\mathrm{F}$ & + & - \\
\hline Squamous $\mathrm{Ca}$ & 11 & $44 \%$ & $51-78 \mathrm{yrs}$ & 9 & 2 & 9 & 2 \\
\hline Adeno $\mathrm{Ca}$ & 8 & $32 \%$ & $29-72 \mathrm{yrs}$ & 5 & 3 & 6 & 2 \\
\hline Poorly differentiated $\mathrm{Ca}$ & 5 & $20 \%$ & $50-76 \mathrm{yrs}$ & 5 & - & 4 & 1 \\
\hline $\begin{array}{c}\text { Adenoid cystic Ca } \\
\text { (Figure 2) }\end{array}$ & 1 & $4 \%$ & 44 yrs & 1 & - & I & \\
\hline
\end{tabular}

Ca-carcinoma, Cyto - cytology, M-male, $\mathrm{F}$-female 


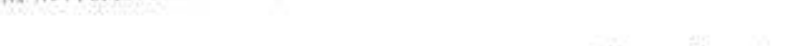

Partial treatment of preumonia either due to inadequate dose, duration or insensitive antibiotics results in unresolved pneumonia with resultant complications like lung abseess and empyema. Approximately sixteen percenl of paticnts in our study showed pneumonia and its resultant complications. The biopsy material was nondiagnostic in $13.4 \%$ of patients. The biopsy size bcing too small for conclusive diagnosis and the absence of issue after processing is a common problem in brenchoscopic biopsies.

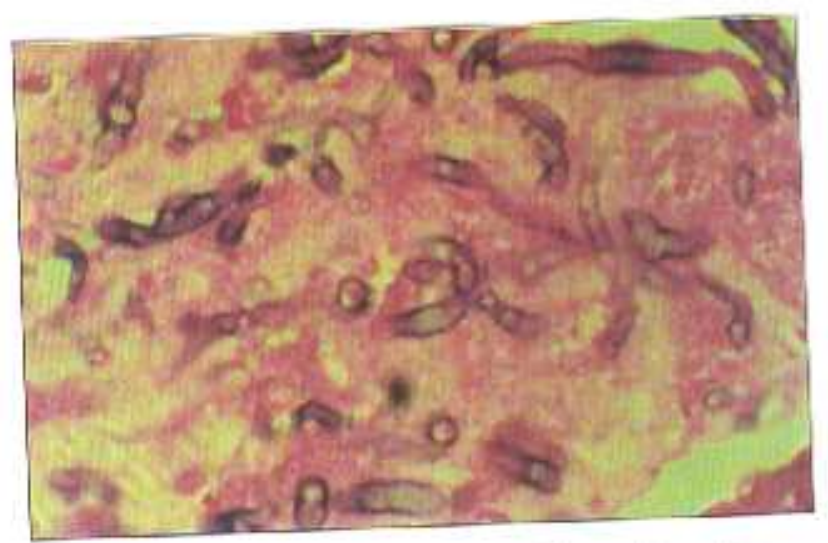

Figure 1 - Aspergilloma of lung showing branched hyphat ( $H \& E 400$ )

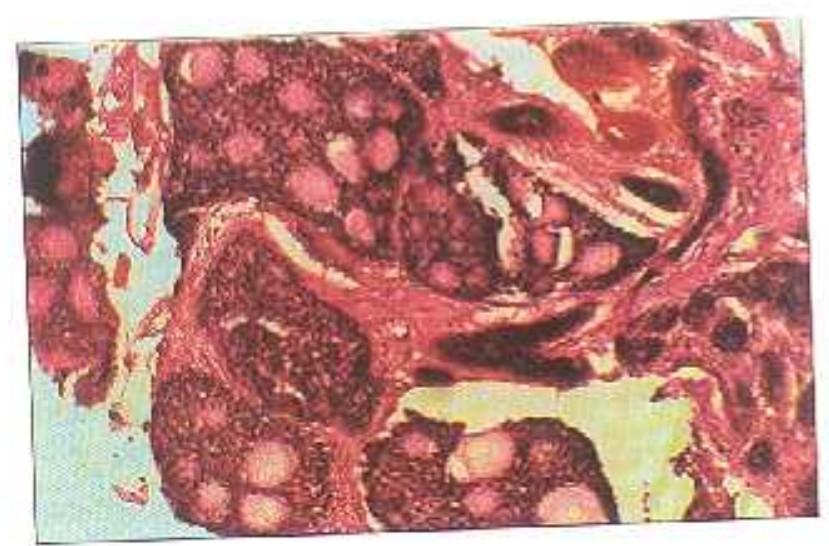

Figure 2 - Adenoid cystic carcinoma of the ling ( $H$ \& E 200)

\section{Acknowledgments}

We thank Dr.Ruchira Fernando, Consultant Itistopathologist. NHSL, Colombu and the doctors and stalf of the chest clinic, Kalutara for their assistance.

\section{References}

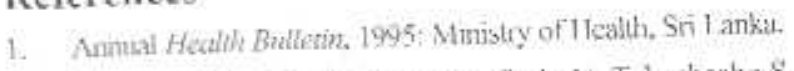

2. Nagomew N, Sauto Y. Imani T. Suda N. Takashashs S.

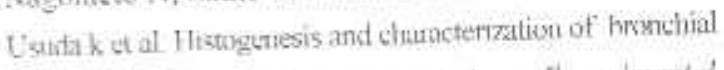
carcinuma observed in heavy smookers. Experimenial medictue 1987:183:265-284.

3. Itoner $K$, Bentrup 7. Russell UG. Mycobacterial peryistence: adoptation to a changing enviroument. Tremis in mucrobiniow, 2001:9:\$97 - 6155.

4. Zahrk: TC. Moleculut mechanisms requlatung persixtent myeobacterum tubersilissts infecrion. Afichoses and infection 2002:5:154-67.

5. Gerd 1, Hetur T. Phappe L. Actim S. Richatd W The refurt of tubercuksis. Diagnastic Mirobulogy and Infectuos fifeusey, 1999;34: 130 - 140 . .

6. Michael S. Glickman W, Jacohs J, R Microbial Puthogencsis of Mycubacterum tuberculosis Coll 2001:104: $477-4 \times 5$.

7. Pabio J B, Barin M, Natakta E Kurepuna, Barry N Kresswirth, Global dissemination of Mycobacterium

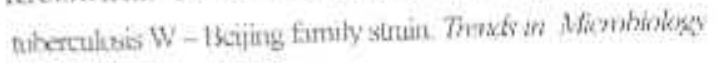
$2042 ; 10: 45-52$.

8. Annual Healih Bulletin 2001, Ministy of Health, Sri Lanka 